\title{
STUDY OF BIOLOGICAL SYNTHESIZED SILVER NANOPARTICLES OF AQUEOUS EXTRACT OF IMPERATA CYLINDRICA AGAINST BACTERIAL CONTAMINANTS FROM DOMESTIC WASTE WATER
}

\author{
Vicky MANI, Uma RAMASWAMY ${ }^{*}$ \\ PG \& Research Department of Biochemistry, Dwaraka Doss Goverdhan Doss Vaishnav College, Arumbakkam, \\ 600106 Chennai, Tamilnadu, India
}

Received 31 October 2020; accepted 26 January 2021

\begin{abstract}
Highlights
W Water resources in many parts of the country are getting depleted and water quality has deteriorated. Almost all the surface water resources are contaminated by pollutants and bacterial contamination, makes them unfit for human consumption.

- Green synthesis of nanoparticle from plant sources has diverse natures with greater stability and make use of ecofriendly, nontoxic safe reagents and also cheaper.

> Nanoparticles has wide application in biomedical field and silver metal was widely used.

Alternate strategy to treat domestic waste water and to maintain water quality that is free from harmful organism.

$>$ Role of Silver nanoparticles of Imperata cylindrica in controlling bacterial contaminants in domestic waste water.
\end{abstract}

\begin{abstract}
The present study focus on the green synthesis and characterization of Imperata cylindrica silver nanoparticle and its efficiency against isolated bacterial contaminants from domestic waste water. $5 \%$ aqueous Imperata cylindrica extract (AEIC) was treated with $1 \mathrm{mM}$ concentration of Silver Nitrate at $37{ }^{\circ} \mathrm{C}$ for silver nanoparticle synthesis. Domestic waste water treated with AEIC and AgNP's of IC with different time durations (12, 24 and 48 hrs). Selective agar media's is used for isolation of specific bacterial species. Surface Plasmon resonance occurred at $430 \mathrm{~nm}$ for $1 \mathrm{mM}$ silver nitrate and AgNP's are spherical and size ranges from 70-80 nm. As the incubation time proceeds after 12, 24 and 48 hours the number of colonies decreased in AEIC and AgNP treated samples. These results showed that AgNP's of I.cylindrica treated sample has the good ability to inhibit E.coli, Salmonella, Phosphate solubilizing bacteria and Shigella in domestic sewage water when compared to AEIC in 48 hours.
\end{abstract}

Keywords: silver nanoparticle, Imperata cylindrica, domestic waste water, antibacterial.

\section{Introduction}

Nanotechnology plays an important role in producing and utilizing nano size particles (Khatoon et al., 2017). Nanoparticle synthesis by green chemistry reduces or eliminates use of hazardous substances by utilizing plant extract (Thombre et al., 2014). Silver nanoparticle used in various field such as sensor, peptide probe, antimicrobial, wound healing and also as catalyst (Mohanapuri et al., 2008; Nam et al., 2003; Ananth et al., 2011; Kiruba Daniel et al., 2010, 2012). Silver nanoparticle effective against bacteria, virus at low concentration and without any side effects to human. Imperata cylindrica belong to the kingdom Plantae and family Poaceae, commonly known as "Dharbai pillu" it is native to South East Asia. Imperata cylindrica used in traditional Chinese medicine (Firdhouse \& Lalitha, 2013). It has pharmacological effects such as Febrile, Anthelmintic, Anti diabetes, Anti diarrohea and used in treatment of wound healing and Nose bleeding (Gangula et al., 2011). Comparative study of biological synthesized silver Imperata cylindrica on its efficiency against bacterial contaminants isolated from domestic waste water was carried out.

${ }^{*}$ Corresponding author. E-mail: uma@dgvaishnavcollege.edu.in 


\section{Materials and methods}

\subsection{Collection and authentication of Imperata cylindrica}

Imperata cylindrica plant was collected from Avadi, Chennai and it was authenticated by Director of Plant Anatomy Research Centre, West Tambaram, Chennai (Reg no: PARC/2017/3437).

\subsection{Preparation of aqueous extract of the Imperata cylindrica}

Stem and leaves of Imperata cylindrica were washed in tap water, shade dried, powered in blender and kept in air tight container. 30 gram of plant powder was immersed in $100 \mathrm{ml}$ of Milliq water, kept in orbital shaker at $37^{\circ} \mathrm{C}$ for $24 \mathrm{hrs}$. Extract was filtered in whatmann filter paper no. 1 and dried in hot air oven at $60{ }^{\circ} \mathrm{C}$.

\subsection{Preparation of aqueous extract of the Imperata cylindrica for silver Nanoparticle synthesis}

$5 \mathrm{~g}$ of dried stem and leaves of Imperata cylindrica was crushed finely and mixed in $100 \mathrm{ml}$ of Milliq water and kept in shaker at $37{ }^{\circ} \mathrm{C}$ for one hour then filtered with Whattman number 1 filter paper and then extract was made up to $100 \mathrm{ml}$ with distilled water. The extracts was stored at $4{ }^{\circ} \mathrm{C}$ and used for silver Nano synthesis.

\subsection{Preparation of Silver nitrate $\left(\mathrm{AgNO}_{3}\right)$ solution of one Millimolar}

$0.084 \mathrm{~g}$ of silver nitrate was weighed and dissolved in $500 \mathrm{ml}$ of distilled water and stored in brown bottle.

\subsection{Biosynthesis of Silver Nanoparticles}

$100 \mathrm{ml}$ of Imperata cylindrica extract was mixed to $900 \mathrm{ml}$ of $1 \mathrm{mM}$ concentration of aqueous $\mathrm{AgNO}_{3}$ and kept in room temperature at dark condition.

\subsection{Characterization of Silver Nanoparticles}

\subsubsection{UV-Visible Spectroscopy}

Optical density was measured from a wave length of 290 $700 \mathrm{~nm}$ using the JASCO spectrophotometer.

\subsubsection{Fourier Transform Infra-red Spectroscopy (FTIR)}

Bruker-Alpha Spectrometer was used for FTIR analysis to identify the biomolecules responsible for the formation of silver nanoparticle.

\subsubsection{Scanning Electron Microscopy (SEM)}

SEM analysis was carried out to determine the size and shape of the silver nanoparticles using Hitachi SU 6600.

\subsection{4. $X$-ray diffraction}

$\mathrm{XRD}$ analysis powder sample was analysed to confirm the crystalline nature of silver metal using Panalytical's.

\subsection{Antibacterial effect of Silver Nanoparticles and Aqueous extract of Imperata cylindrica}

Presence of Bacteria in Domestic waste water was determined by pour plate method (Dosoky et al., 2015). Domestic sewage water was collected from Taramani Chennai Pour plating was done on Domestic waste water with $10^{4}$ dilution. Three conical flask in each flask has $100 \mathrm{ml}$ of domestic waste water (sample a), domestic waste water treated with $10 \mathrm{mg}$ of Aqueous plant extract (sample b) and domestic waste water treated with $10 \mathrm{mg}$ of AgNPs were kept in orbital shaker for 12, 24 and 48 hours at $37^{\circ} \mathrm{C}$. Based on the colour and morphology of the colonies in nutrient agar plate, Macconkey agar, Deoxycholate citrate agar, Xylose - Lysine Deoxycholate Agar and Pikovskaya's Agar medium (selective media) was used for isolation of specific bacterial species. Domestic waste water treated samples at different time intervals such as 12, 24 and 48 hours with $10^{4}$ dilution was used for pour plating.

\section{Results and discussion}

\subsection{UV Visible spectrum analysis}

Ultra violet - visible spectra peak or SPR (surface plasmon resonance) band centered at $430 \mathrm{~nm}$ was observed for Imperata cylindrica silver nanoparticles (Figure 1).

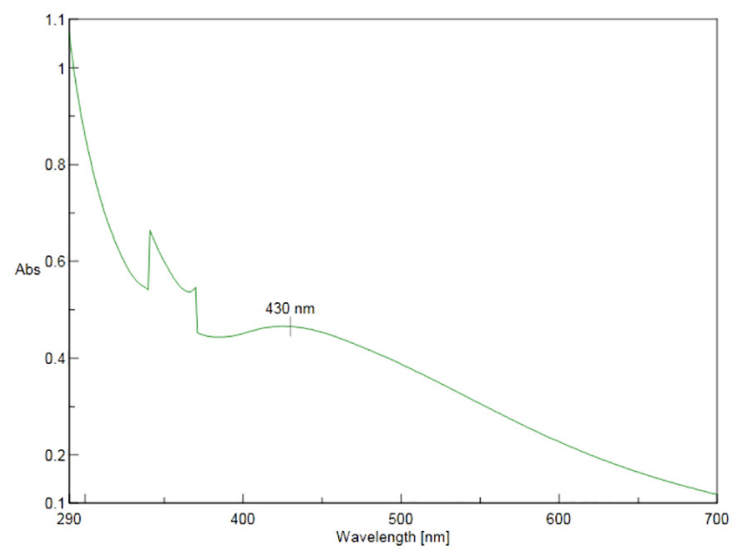

Figure 1. UV - Visible spectra of Aqueous extract of Imperata cylindrica with $1 \mathrm{mM}$ Silver Nitrate

\subsection{Fourier Transform Infra-red Spectroscopy}

Absorption bands at 3233, 1267, 1069, 1030, 858, $787 \mathrm{~cm}^{-1}$ are observed. The band of $3233 \mathrm{~cm}^{-1}$ is attributed to $\mathrm{OH}$ stretch, band at $1267,1069,1030 \mathrm{~cm}^{-1}$ is due to the stretching vibration of carbonyl group which may be derived from compounds such as flavonoid, terpenoids or polysaccharides in the extract. The bands at 858 \& $787 \mathrm{~cm}^{-1}$ corresponds to bond C-H "oop" and functional group aromatics (Figure 2).

Additional bands appear at $1695 \mathrm{~cm}^{-1}$ which is assigned to the stretching vibration of $\mathrm{C}=\mathrm{O}$ group.

In addition it is also observed that band $1069 \mathrm{~cm}^{-1}$ disappears after the formation of AgNP's which is attributed 


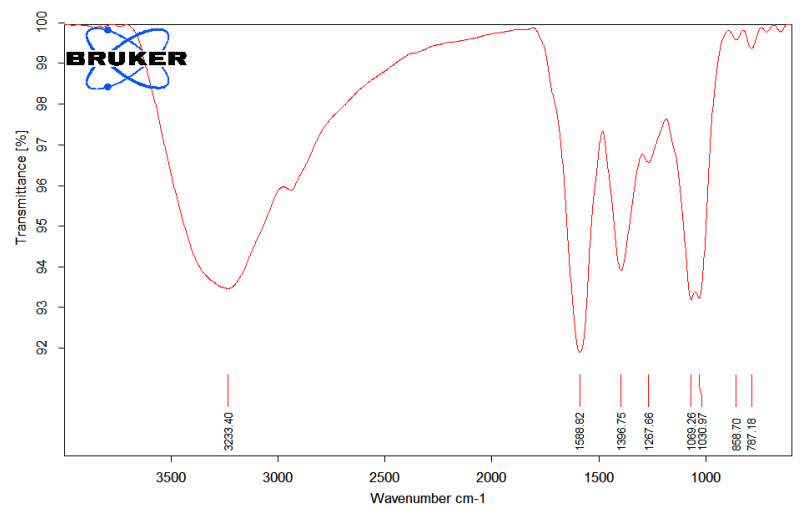

Figure 2. FTIR analysis of Aqueous of Imperata cylindrica

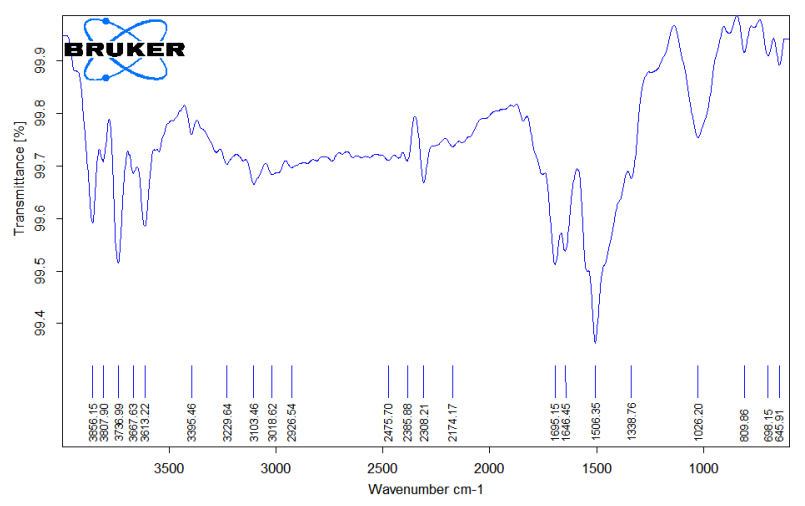

Figure 3. FTIR analysis of Silver Nano particle of Imperata cylindrica $(1 \mathrm{mM})$

to the stretch vibration of -C-O bond. It clearly indicates that the alcohol group is converted to carbonyl group $(\mathrm{C}=\mathrm{O})$ during the formation of silver nanoparticle (Figure 3).

\subsection{SEM}

The AgNP formed were spherical in shape, agglomerated and poly disperesed. The AgNP's diameter varied from 70-80 nm (Figure 4).

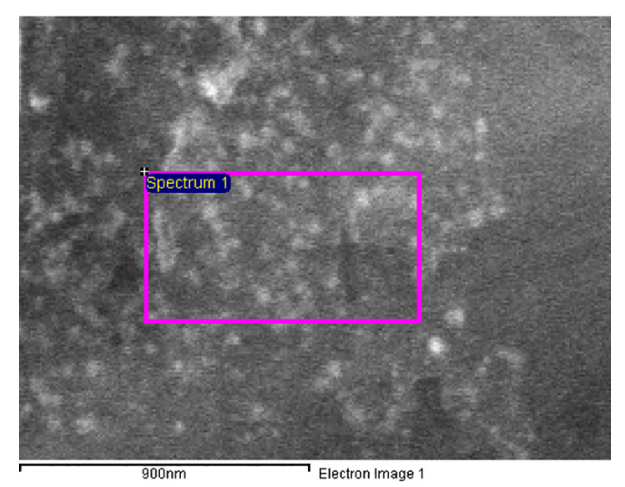

Figure 4. SEM analysis of Silver Nanoparticle of Imperata cylindrica

\subsection{XRD}

Diffraction pattern of synthesized AgNP's showed peaks at $38.19^{\circ}, 46.23^{\circ}$ and $64.24^{\circ}$ corresponding to lattice plane (111), (200), and (220) respectively. The peak match with the Joint Committee on Powder Diffraction Standards (file no 04-0753) which proves the formation of crystal AgNPs (Swanson \& Tatge, 1953) (Figure 5).

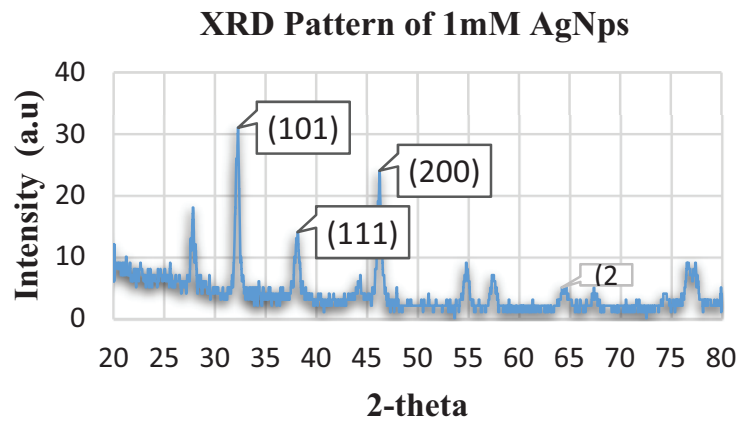

Figure 5. XRD pattern of $1 \mathrm{mM}$ AgNPs of Imperata cylindrica

\subsection{Efficiency of antibacterial contaminants of domestic waste water}

Mean values of total bacterial count of domestic waste water in Xylose - Lysine Deoxycholate Agar (Figure 6 and Plate 1), Pikovskaya's Agar medium (Figure 7 and Plate 2), MacConkey agar (Figure 8 and Plate 3) and Deoxycholate citrate agar (Figure 9 and Plate 4). The study revealed the presence of Shigella, Phosphate solubilizing bacteria, E.coli and Salmonella in the domestic waste water sample.

Treatment of domestic waste water with the aqueous extract of I.cylindrica and AgNP's of I.cylindrica showed growth inhibition of these pathogens. As the incubation time proceeds after 12, 24 and 48 hours the number of colonies decreased in control, aqueous extract of I.cylindrica and AgNP's treated samples. Nearly 168 colonies of Shigella reported in domestic waste water sample (Xylose Lysine Deoxycholate) and the AEIC and AgNP's treated sample treated sample count was reduced to 48 and zero colonies in 12 hours respectively.

In Pikovskaya's agar medium 120 colonies of PSB was found as the time proceeds the count was reduced and reaches up to 83 in $48 \mathrm{hrs}$ control sample. AgNP's treated sample there was no colonies at $48 \mathrm{~h}$. In MacConkey medium E.coli count was 197 in control and it was decreased to 40 colonies in AgNP's treated sample in 12 hours.

In Deoxycholate citrate agar, AgNP's treated samples, Salmonella colonies were significantly reduced than control sample in 24 hrs incubation time. These results showed that AgNP's has the good ability to inhibit E.coli, Salmonella, PSB and Shigella in Domestic waste water. Antibacterial effect of silver nanoparticles was exhibited by inactivation of respiratory chain dehydrogenase, thereby excess production of ROS generation which inhibited respiration and growth of cells (Quinteros et al., 2016; Su et al., 2009). Uptake of phosphate and release of mannitol, 
succinate, proline and glutamine was inhibited in the presence of silver. Silver nanoparticles widely used as antibacterial control system by acting as growth inhibitor in various micro organisms (Schreurs \& Rosenberg, 1982).

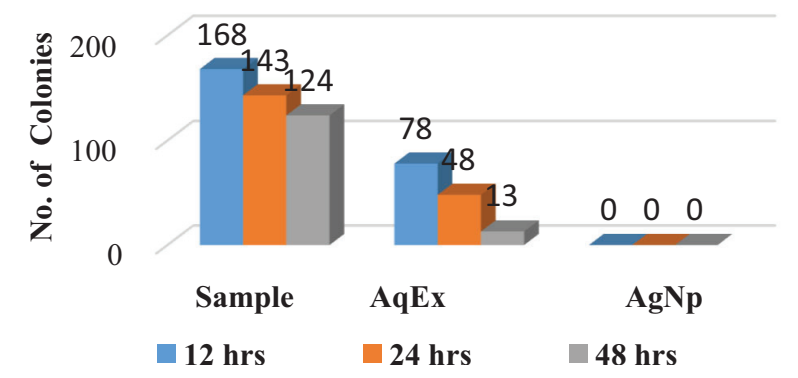

Figure 6. Total bacterial count in Xylose - Lysine Deoxycholate Agar (Shigella) - values are expressed as Mean $(n=3)$

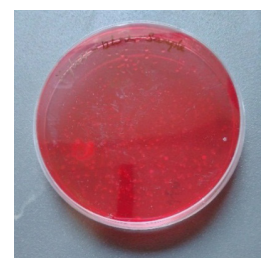

a)

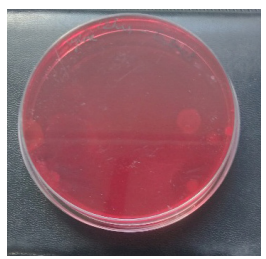

b)

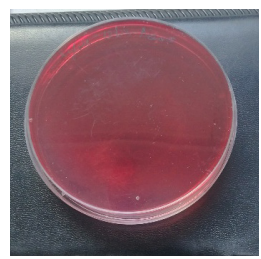

c)
Plate 1. Sample treated with AgNP and AEIC of Imperata cylindrica in 12 hrs: a - Control sample; b - Treated with AEIC; c - Treated with AgNP

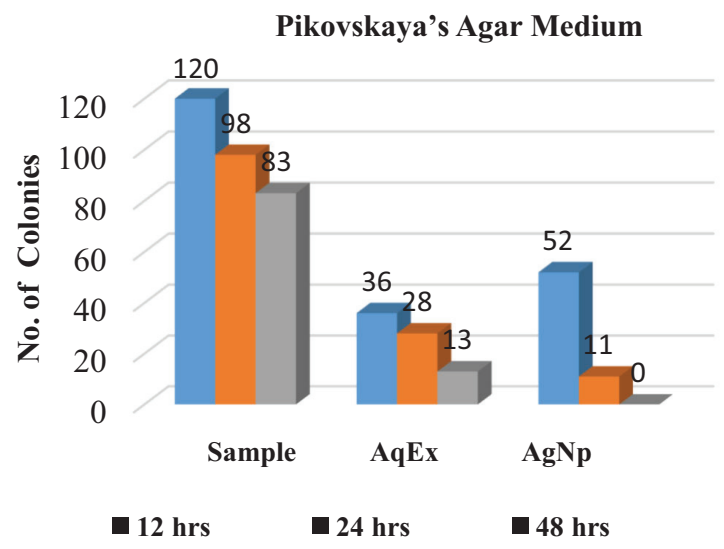

Figure 7. Total bacterial count (PSB) in PSB Pikovskaya's Agar Medium - values are expressed as Mean $(n=3)$

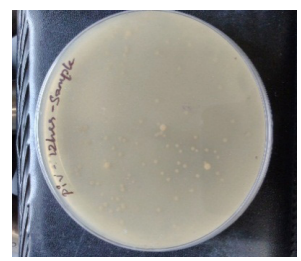

a)

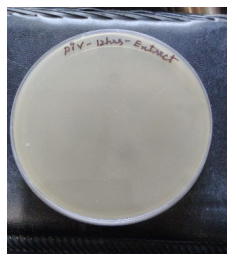

b)

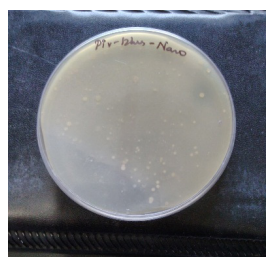

c)
Plate 2. Sample treated with AgNP and AEIC of Imperata cylindrica in 12 hrs: a - Control sample; b - Treated with AEIC; $c$ - Treated with AgNP

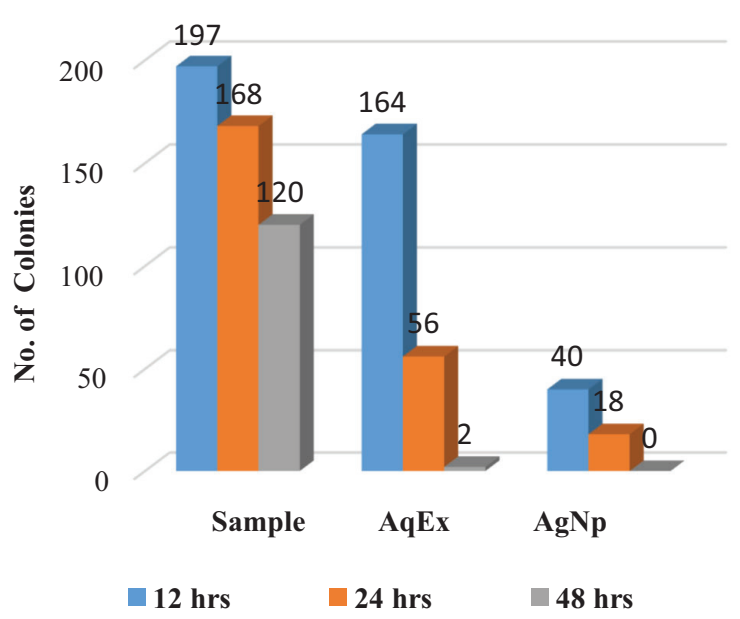

Figure 8. Total bacterial count (E.coli) in Macckonkey Agar values are expressed as Mean $(n=3)$

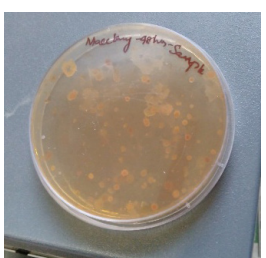

a)

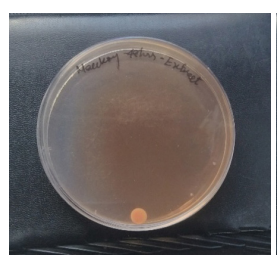

b)

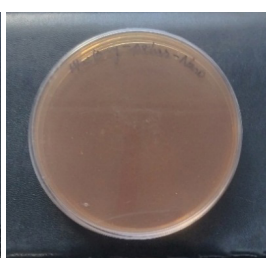

c)
Plate 3. Sample treated with AgNP and AEIC of Imperata cylindrica in 48 hrs: a - Control sample; b - Treated with AEIC; $c$ - Treated with AgNP

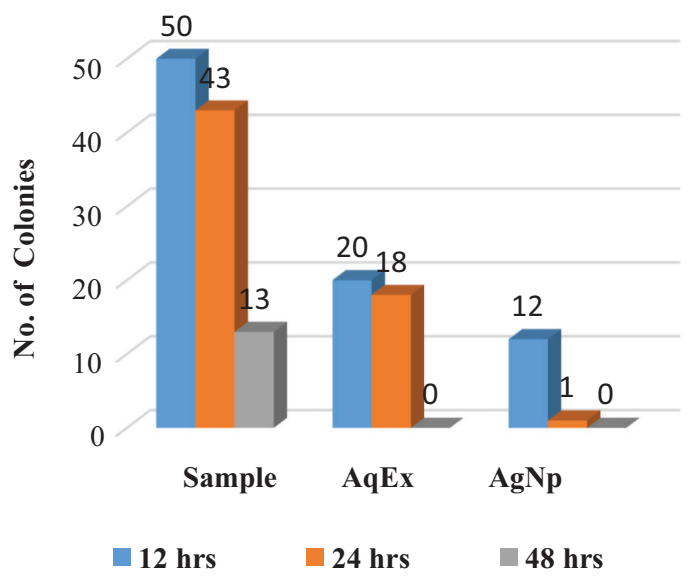

Figure 9. Total bacterial count (Salmonella colonies) in Deoxycholate citrate agar - values are expressed as Mean $(n=3)$

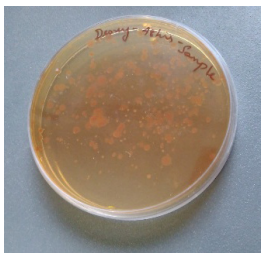

a)

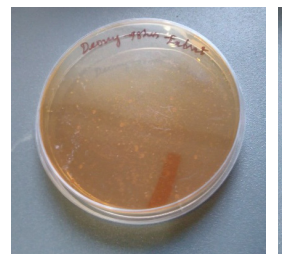

b)

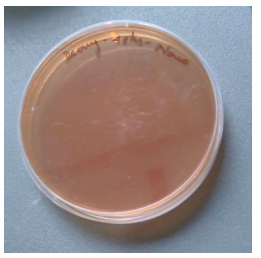

c)
Plate 4. Sample treated with AgNP and AEIC of Imperata cylindrica in 48 hrs: a - Control sample; b - Treated with AEIC; $c$ - Treated with AgNP 


\section{Conclusions}

Present studies show biological synthesized silver nanoparticle has high potential against pathogenic bacteria in domestic waste water than plant aqueous extract of Imperata cylindrica. This property may have a promising application in treating the domestic waste water and it is cost effective than chemical treatment as well as eco-friendly to the environment. Further studies need to be done on large scale production of silver nanoparticle for the field trials on domestic waste water.

\section{References}

Ananth, A. N., Daniel., S. C. G. K., Sironmani, T. A., \& Umapathi, S. (2011). PVA and BSA stabilized silver nanoparticles based surface - enhanced plasmon resonance probes for protein detection. Colloids and Surfaces B: Biointerfaces, 85(2), 138-144. https://doi.org/10.1016/j.colsurfb.2011.02.012

Dosoky, R., Kotb, S., \& Farghali, M. (2015). Efficiency of silver nanoparticles against bacterial contaminants isolated from surface and ground water in Egypt. Journal of Advanced Veterinary and Animal Research, 2(2), 175-184. https://doi.org/10.5455/javar.2015.b79

Firdhouse, M. J., \& Lalitha, P. (2013). Green synthesis of silver nanoparticles using the aqueous extract of Portulaca oleracea (L). Asian Journal of Pharmaceutical and Clinical Research, 6(1), 92-94.

Gangula, A., Podila, R., Ramakrishna, M., Karanam, L., Janardhana, C., \& Rao, A. M. (2011). Catalytic reduction of 4-Nitrophenol using Biogenic Gold and Silver nanoparticles derived from Breynia rhamnoides, 27(24), 15268-15274. https://doi.org/10.1021/la2034559

Khatoon, N., Mazumder, J. A., \& Sardar, M. (2017). Biotechnology applications of green synthesized silver nanoparticles. Journal of Nanoscience: Current Research, 2(1), 107.

Kiruba Daniel, S. C. G., Nehru, K., \& Sivakumar, M. (2012). Rapid biosynthesis of silver nanoparticles using Eschornia crassipes and its antibacterial activity. Current Nanoscience, 8(1), 125-129. https://doi.org/10.2174/1573413711208010125

Kiruba Daniel, S. C. G., Tharmaraj, V., Anitha Sironmani, T., \& Pitchumani, K. (2010). Toxicity and immunology activity of silver nanoparticles. Applied Clay Science, 48(4), 547-551. https://doi.org/10.1016/j.clay.2010.03.001

Mohanapuri, P., Rana, N. K., \& Yadav, S. K. (2008). Biosynthesis of nanoparticles: Technology concepts and future applications. Journal of Nanoparticles Research, 10(3), 507-517. https://doi.org/10.1007/s11051-007-9275-X

Nam, J.-M., Thaxton, C. S., \& Mirkin, C. A. (2003). Nanoparticle-based bio-bar codes for the ultrasensitive detection of proteins. Science, 301(5641), 1884-1886. https://doi.org/10.1126/science.1088755

Quinteros, M. A., Cano Aristizábal, V., Dalmasso, P. R., Paraje, M. G., \& Páez, P. L. (2016). Oxidative stress generation of silver nanoparticles in three bacterial genera and its relationship with the antimicrobial activity. Toxicology in Vitro, 36, 216-223. https://doi.org/10.1016/j.tiv.2016.08.007

Schreurs, W. J., \& Rosenberg, H. (1982). Effect of silver ions on transport and retention of phosphate by Escherichia coli. Journal of Bacteriology, 152(1), 7-13. https://doi.org/10.1128/jb.152.1.7-13.1982

Su, H. L., Chou, C. C., Hung, D. J., Lin, S.-H., Pao, I.-C., Lin, J. H., Huang, F.-L., Dong, R.-X., \& Lin, J.-J. (2009). The disruption of bacterial membrane integrity through ROS generation induced by nanohybrids of silver and clay. Biomaterials, 30(30), 5979-5987. https://doi.org/10.1016/j.biomaterials.2009.07.030

Swanson, H. E., \& Tatge, E. (1953). Standard X-ray diffraction powder patterns (NBS Circular 539, Vol. 1). United States Department of Commerce, National Bureau of Standards.

Thombre, R., Chitnis, A., Kadam, V., Bogawat, Y., Colaco, R., \& Kale, A. (2014). A facile method for synthesis of biostabilized silver nanoparticles using Eichhornia crassipes (Mart.) Solms (Water hyacinth). Indian Journal of Biotechnology, 13, 337-341. 